\title{
Equally weighted portfolios and "momentum effect": an interesting combination for unsophisticated investors?
}

\author{
Fabio Civiletti ${ }^{1}$ \\ fabio.civiletti@gmail.com | (100000-0003-2484-3400 \\ Carlos Heitor Campani ${ }^{2}$ \\ carlos.heitor@coppead.ufrj.br| @0000-0003-1896-7837 \\ Raphael Roquete ${ }^{2}$ \\ raphael@facc.ufrj.br| @0000-0001-5554-0379
}

\begin{abstract}
This article proposes investment strategies targeted at unsophisticated investors and structured around persistence in returns, especially in the short and medium term ("momentum effect"). Sixty-four equally weighted portfolios were formed, through the variation of five different parameters: size, revision frequency, asset selection indicator, choice criterion, and formation period. The proposed portfolios' performances were assessed from January 2009 to December 2018 and compared to the performance of BOVA11 (Exchange Traded Fund which aims to replicate Ibovespa, the main stock market index in Brazil). Transaction costs were considered. The results corroborate the hypothesis of the "momentum effect". Winner portfolios also were indicated asgood alternatives as investment strategies, since they presented higher median returns and Sharpe ratios than the benchmark, as well as positive alphas. Additional tests showed that transaction costs can significantly impact the portfolios' performances. The analysis presented in this paper shall be relevant to unsophisticated investors, introducing a competitive though easy-to-implement investment strategy.
\end{abstract}

\section{KEYWORDS}

Momentum Effect, Equally Weighted Portfolios, Unsophisticated Investor, Stock
${ }^{1}$ IAE Bordeaux,

Bordeaux, França

${ }^{2}$ Universidade Federal do Rio de Janeiro, Rio de Janeiro, RJ, Brasil

Received: 10/23/2019.

Revised: 10/29/2019.

Accepted: 02/29/2020.

Published Online: 08/10/2020.

DOI: http://dx.doi.org/10.15728/bbr.2020.17.5.2 


\section{INTRODUCTION}

According to a survey published by B3 (Brazil's stock exchange operator) entitled "Ecossistema do Investidor Brasileiro", the Brazilian stock market reached the historical mark of one million investors during April of 2019. In comparison with the same period of the previous year, approximately 400,000 new accounts were opened, meaning an increase of $65 \%$ of the investor base. Among the reasons behind the increasing number of investors are the recent solid performance of equities (Ibovespa, the leading indicator of traded shares, appreciated $15.0 \%$ and $26.9 \%$ in 2018 and 2017, respectively) and the fact that the country's base interest rate has been at an all-time low for more than twelve months, inviting investors to take risks in pursuit of higher returns. Also noteworthy are the strong financial education campaigns promoted by $\mathrm{B} 3$ and by the main local brokers.

Following this symbolic milestone, the number of individual investors is expected to continue to grow in the coming years, given the positive prospects for the Brazilian economy to resume and considering that the volume of investors is still an insignificant portion of the total population, as the current base represents less than $0.5 \%$ of the Brazilian population, while, in the United States, more than $50 \%$ of households invest in shares directly or indirectly, as reported by the Federal Reserve Board in 2016.

Also in accordance with the aforementioned survey, $40 \%$ of active investors in Brazil have assets of up to BRL10,000 invested in the stock market, while the invested estate of three quarters of investors do not surpass BRL 100,000. These figures indicate that a significant portion of the base can be classified as unsophisticated, since they lack technical and/or financial resources for effectively active managing their portfolios (Swensen, 2009). For this investor profile, portfolio management tends to be a challenging task, mainly due to difficulties in accessing relevant information and/or to lack of time for proper data analysis.

This article analyzes active management strategies that are easy to understand and implement, even by unsophisticated investors. Such strategies consist in forming equally weighted portfolios with the assets that achieved higher performance in the previous periods, as measured by the stocks' accumulated return and/or Jensen's alpha. While equally weighted portfolios formed by "winners" were already themes of previous studies, asset selection based on previous alphas is innovative to a certain extent, as there was no history of evaluation of this methodology's effectiveness in the Brazilian stock market so far. The results delivered by the proposed portfolios are compared with the ones achieved during the same period of time by the main Brazilian Exchange Traded Fund, BOVA11, which aims to replicate the performance of the Ibovespa index. That ETF was chosen to represent the passive management alternative, commonly pursued by unsophisticated investors due to the aforementioned restrictions.

Therefore, the study contributes to the discussion regarding the existence of a "momentum effect" in the Brazilian stock market (as there was no consensus between the authors that studied the subject in the past), while also presenting a historically competitive active management strategy, implementable by unsophisticated investors.

\section{LITERATURE REVIEW}

\section{1. "Momentum EFFECT"}

According to the Efficient Market Hypothesis (EMH) formulated by Fama (1970), the price of a stock reflects all publicly available information regarding such equity. In the decades that 
BBR

17

508

followed that publication, several authors questioned this hypothesis by presenting certain market anomalies. One such anomaly is known as the "momentum effect," which consists in the persistence of positive stock returns, especially in the short and/or medium-term.

Jegadeesh and Titman $(1993,2001)$ pioneered the works that identified this phenomenon, by verifying that portfolios long in winner stocks and short in loser stocks achieved positive abnormal results in the US market between 1965 and 1989 and between 1990 and 1997.

Replicating the methodology proposed by Jegadeesh and Titman (1993) in the European market, Rouwenhorst (1998) verified the "momentum effect" in 12 different countries by assessing the behavior of 2,190 stocks between 1978 and 1995. Schiereck, De Bondt, and Weber (1999) also identified this phenomenon in the German stock market, by analyzing the price variation of 357 companies between 1961 and 1991. Mengoli (2004) corroborated the profitability of the strategy in Europe by studying the behavior of the Italian stock exchange between 1950 and 1995 .

In Brazil, such an effect was the object of research for Mussa, Thunder, Famá, and Santos (2008), who replicated the rationale of Jegadeesh and Titman (1993) for the period between 1995 and 2006. These authors analyzed the monthly closing returns of all stocks listed on the São Paulo Stock Exchange and identified the possibility of statistically significant abnormal gains in 03 of the 16 proposed strategies. Applying similar methodologies, research by Pires (2013), Silva Neto, Silva, Raboni and Oliveira (2014), and Leoni (2015) also highlighted the profitability of "momentum effect" based strategies on the Brazilian stock market.

\subsection{EQUALLY WEIGHTED PORTFOLIOS}

When forming a stock portfolio, one of the main decisions for the investor is the weight to be attributed to each asset. According to Benartzi and Thaler (2001), a simple alternative - and commonly employed by unsophisticated investors - is to equally divide the value to be invested between the selected assets.

Markowitz (1952) defends that an investor should always look for portfolios that are on the efficient frontier, as these present an optimized risk-return ratio. Such a concept goes against an equally weighted portfolio; however, several authors have been questioning its applicability. DeMiguel, Garlappi, and Uppal (2009), for instance, tested 14 optimization models and found that none of them were consistently superior to the $1 / \mathrm{N}$ methodology, because gains from optimal diversification were eliminated by errors in parameters estimation. Duchin and Levy (2009) concluded that naive portfolios tend to outperform optimized ones in cases of few assets, while the relationship tends to be opposite in the case of portfolios composed by a higher number of stocks. Kritzman, Page, and Turkington (2010) argue that, in order for optimization to add value to the portfolio, it is necessary to consider a long historical series when estimating the assets' expected returns (which may be a pain point in Brazil).

Faced with these constraints, and considering the simplicity of equally weighting, several authors have studied the results achieved by such methods in the Brazilian stock market, especially with focus on unsophisticated investors. At the beginning of the decade, Thomé Neto, Leal, and Almeida (2011) developed an index of global minimum variance portfolios (for the most liquid Brazilian stocks and identified that the results of the strategy outperform Ibovespa and are comparable to $1 / \mathrm{N}$ portfolios. Subsequently, Santiago and Leal (2015) evaluated naive portfolios composed of 06 to 16 stocks, reviewed every four months and formed by the stocks with highest Sharpe ratio (SR) in the previous period. The authors found that these portfolios outperformed equity funds over the assessed period (1998 to 2011), despite having higher standard deviation. Campani and Leal (2016) conducted a study suggesting two indexes that were later supported by 
the specialized Brazilian newspaper Valor Econômico. The authors found that equally weighted portfolios formed of up to 20 stocks outperformed most national equity funds and that their results were comparable to the performance of the minimum variance portfolio with restricted weights.

Afterwards, Battaglia and Leal (2017) focused on the asset selection criteria and evaluated randomly formed naive portfolios. The authors argue that investors were more likely to achieve higher returns by applying this strategy than through equity funds. In a more recent study, Carneiro and Leal (2017) analyzed the performance of equally weighted portfolios with 05 to 30 stocks, selected according to various criteria (value, momentum, liquidity, and Sharpe ratio), and reviewed every four months. The authors concluded that cumulative returns of $1 / \mathrm{N}$ portfolios often outperformed both the stock market index and equity funds, especially when the amount invested exceeds US\$25,000, mitigating the impact of transaction costs. In the period evaluated (2003 to 2012), the portfolio which consisted of the 30 stocks that achieved highest returns in the previous four-month period showed an average daily return of $0.11 \%$ (compared to $0.09 \%$ of the Ibovespa) and a standard deviation of $1.61 \%$. (compared to $1.85 \%$ of that index), both significant at a $5 \%$ level.

\section{DATA AND METHODOLOGY}

\subsection{ReSEARCH UNIVERSE}

The study analyzed the viability of the proposed strategies by evaluating the behavior of the Brazilian stock market over the last ten years (from January 2009 to December 2018). The time horizon includes the resumption of the world economy after the subprime mortgagecrisis (starting from July 2007) and comprises atypical events that significantly impacted the Brazilian stock market (both positively and negatively), such as the presidential impeachment process that took place in 2016 and investigations from federal police regarding corruption cases in high political spheres.

The stocks suitable for selection were the ones that took part in the Brazil 100 Index ( $\mathrm{IBrX}$ 100) on the portfolio's revision dates. This index is updated every four months and is composed of the 100 most tradable and representative stocks in the Brazilian market. Such criterion works as a liquidity filter (an important parameter for unsophisticated investors), without limiting too much the possible options for portfolios' formation. Stocks of companies under judicial or extrajudicial recovery, penny stocks, and Brazilian Depositary Receipts are not included in the IBrX 100. The daily historical composition of the index was obtained through the platform UP2DATA ON DEMAND, B3's online data trading store.

Over the period evaluated, 177 different companies (214 tickers) participated in the IBrX 100 for at least one four-month period. The difference between the number of companies and the number of tickers occurs because of changes in trading codes over the years and also because both preferred and common shares of the same company may be selected to compose the index; moreover, at the same time. The daily closing prices of each stock were gathered through Economatica $^{\oplus}$ database and adjusted values were considered, so that such variations reflected only genuine valuations and devaluations of the companies. For the dates when a given share was not traded, the study considered that there was no price change, which means that the last available price was replicated. 


\subsection{CRITERIA FOR PORTFOliO FORMATION}

The portfolio formation process was based on five parameters: size (number of stocks), revision frequency, indicator used for stock selection, selection criteria, and period of formation. Based on the possible options determined for each of these parameters (described below), 64 distinct portfolios were evaluated.

Four possible size options were analyzed: 5, 10, 15, and 20 stocks per portfolio. The research focused on small portfolios for two main reasons: to reduce the impact of transaction costs on net profitability and to generate easily manageable portfolios, even for unsophisticated investors. The authors have not intended to generate fully diversified portfolios, however, according to Brito (1989), most gains derived from diversification may be obtained with small portfolios composed of about 8 stocks (being the positive effects of diversification negligible for portfolios with 15 or more stocks), while Oliveira and de Paula (2008) stated that 12 stocks resulted in the optimal degree of diversification for home broker users.

The study evaluated two possible revision frequencies: annually, and on a quarterly basis. These options were chosen in order to verify whether more active management strategies would present higher results after the discount of the presumably higher transaction costs, thus justifying a bigger time expenditure from the investor. In cases of annual revision, portfolios were always reviewed on the first business day of the year, while in cases of four-month period revision, the update was made on the first business days of January, May, and September.

For stock selection, two possibilities were considered: past accumulated logarithmic returns or past alphas (Jensen, 1968). The daily logarithmic return of each stock was calculated according to Equation 1, being $R_{i, t}$ the logarithmic return of asset $i$ on date $t, P_{i, t}$ the adjusted closing price of asset $i$ on the date day $t$, and, naturally, $P_{i, t-1}$ the previous adjusted closing price of asset $i$.

$$
R_{i, t}=\ln \left(P_{i, t}\right)-\ln \left(P_{i, t-1}\right)
$$

The selection based on past alphas was inspired by the work of Mendonça Júnior, Campani, and Leal (2017), which focused on equity funds. The stock's alphas were obtained by linear regressions through the least squares method. The intercept of the linear regression described in Equation 2 is the estimated alpha for asset $i\left(\alpha_{i}\right)$, being $R_{i . t}$ the daily return of the analyzed asset, $R_{f . t}$ the risk-free rate, and $R_{m . t}$ the daily market return. To represent the risk-free rate, the daily SELIC over rate was selected, whereas the Ibovespa index was chosen to represent the market. The angular coefficient is the asset's beta, while the term $\varepsilon_{i, t}$ represents the error, being its expected value null.

$$
\left(R_{i, t}-R_{f, t}\right)=\beta_{i}\left(R_{m, t}-R_{f, t}\right)+\alpha_{i+} \varepsilon_{i, t}
$$

Half of the portfolios were generated considering a formation period (that is, the time horizon designated to analyze the stock's past performance) of four months, while the other half was generated considering one year for the formation period. Both winner portfolios (composed of the stocks that performed better over the formation period, based on the indicator defined for that portfolio) and loser portfolios (composed of the stocks that presented the worst performance in the period of formation, also based on the indicator designated for that portfolio) were constituted.

All portfolios were equally weighted, disregarding, for simplification purposes, minimum lot size. The initial investment for all cases was BRL 10,000, and there were no restrictions regarding both preferred and ordinary shares taking part in the same portfolio simultaneously. 


\subsection{TRANSACTION COSTS AND TAXES}

For each transaction, $0.031615 \%$ of the purchase/sale value of the share was computed as a variable cost, of which $0.0275 \%$ related to the settlement rate and $0.004115 \%$ related to operational fees, both charged by B3.

For each purchase/sale, a fixed cost of BRL 5.00 was also computed, related to brokerage fees. This is an intermediate value amongst the ones established by the largest brokerage firms in the country. At this point, some Brazilian brokers do not charge brokerage fees, although, such cost was computed for conservative matters, as that may be a transitory measure, focused in attracting new investors but unsustainable in the long run.

In each revision, it was considered that all stocks that comprised the portfolio until that moment were sold, and the newly selected ones purchased. Thus, conservatively, if an asset was selected for the portfolio for two consecutive periods, the transaction costs related to its sale and repurchase were computed.

For profitable operations (considering the difference between the total purchase value and the net revenue obtained through the shares' sale, after the discount of transaction costs), a 15\% income tax was computed, except in cases where the total sales within the month added up less than BRL 20,000. For purposes of simplification, it was considered that the payment of the income tax would be immediately after the transaction, although, in Brazil, a such tax may be paid until the last business day of the month that follows the month of the sale.

\subsection{Portfolio nomenclature}

The generated portfolios were named according to the following pattern: $R_{f}-F_{p} C-N_{-} I$, where $R_{f}$ is the revision frequency, $F_{p}$ the formation period, $C$ the selection criterion, $N$ the number of assets and $I$ the indicator considered for selection. For illustrative purposes: the "Q-12W-20_ $\alpha$ " portfolio was updated every four-month period and consisted of the 20 stocks that achieved the highest alphas in the twelve months prior to the portfolio revision dates.

\subsection{Performance indicators}

For evaluating the proposed portfolios' performances, two indicators were adopted: Jensen's alpha and Sharpe ratio.

The portfolios' alphas were calculated according to Equation 2. As a proxy for the market return, the BOVA11 ETF (created in 2008 and currently very liquid) was selected. Despite the authors' preference for the IBrX 100 for representing the market, the main fund that aims to replicate such index (BRAX11) was created in 2011, after the beginning of this research's time horizon.

The ex-post Sharpe ratio of each portfolio $i$ was calculated as in Equation 3 (Sharpe 1966), where $R_{i, t}$ is the portfolio's daily net profit, $R_{f, t}$ is the risk-free rate - represented by the daily SELIC over rate - and $s_{i}$ is the standard deviation of the daily differences of the numerator over the selected time horizon (January 2009 to December 2018).

$$
I S_{i}=\frac{\overline{\left(R_{i, t}-R_{f, t}\right)}}{s_{i}}
$$


BBR

17

512

\section{RESULTS}

\subsection{WinNER VS. LOSER PORTFOLIOS (THE "MOMENTUM EFFECT")}

Table 1 gathers the descriptive statistics for the 32 portfolios formed based on past returns, while Table 2 presents the descriptive statistics for the 32 portfolios formed based on past alphas. In both Tables, the portfolios are arranged in pairs: the first portfolio consists of winner assets and the second consists ofloser ones.

Over the assessed period (January 2009 to December 2018), each portfolio generated 2,470 daily net profits. Tables 1 and 2 gathered the medians, standard deviations, and extreme values of such daily net profits, as well as the net profit of each portfolio in the period, allowing performance comparisons to be made.

The median of each portfolio comprising winner stocks (W) was compared with that of the portfolio consisting of loser stocks (L). The Shapiro-Wilks test rejected the hypothesis of normality at the level of $1 \%$ for all 64 portfolios generated, so the nonparametric one-tailed Mann-Whitney-Wilcoxon test was chosen to assess the statistical significance of the differences between the medians.

All winner portfolios formed based on past earnings showed higher median net profits than their respective losers. In seven of the cases, the difference was significant at the level of $10 \%$, being that such significance concentrated in the portfolios was reviewed every four-month period. Another fact that stands out is that all winner portfolios have shown lower standard deviations than their respective losers over the evaluation period.

For portfolios formed based on past alphas, the scenario was similar. Again, all winner portfolios achieved higher median net profits than their respective losers, being, in five of the cases, the difference significant at the level of $10 \%$. Such significance was once more concentrated in portfolios reviewed every four months. As in the case of portfolio formation based on past earnings, all winner portfolios shown lower standard deviations than their respective losers.

Summing up, all 32 portfolios composed of winner stocks outperformed those composed of loser assets, maintained the remaining parameters (revision frequency, period of formation, size, selection indicator and criteria).

It is worth mentioning that the eight winner portfolios formed based on past twelve-month performance and reviewed every four months stood out, as all of them presented statistically higher medians than their respective losing portfolios at the level of $10 \%$. There is a plausible reason for such a result: reviewing the portfolio each four-month period leads to the capture of short-term return persistency, while more extended formation periods increase the likelihood of selecting assets that are, in fact, superior to the others (not those that achieved positive results in the past due to specific factors).

\subsection{WinNER PORTFOlios VS. PASSIVE MANAGEMENT (INVESTMENT STRATEgIES)}

The previous results lead to the next analysis, which is focused on identifying whether winner portfolios are not only superior to their respective losers, but also an interesting alternative for unsophisticated investors. Table 3 compares the results achieved by the winner portfolios to the performance of BOVA11 over the same time period.

All winner portfolios achieved median net profit higher than the BOVA11 ETF over the period evaluated, being three of such differences significant at level of $10 \%$. Of the portfolios formed, $75 \%$ shown lower standard deviations than the index fund, presenting themselves as interesting investment opportunities even for more risk averse investors. 
Table 1

Portfolios formed based on past returns

\begin{tabular}{|c|c|c|c|c|c|}
\hline Portfolio & Median & Standard deviation & Maximum & Minimum & Net return \\
\hline Q-12W-5_r & $15.52^{* *}$ & 24.56 & 9.03 & -13.78 & 13.47 \\
\hline Q-12L-5_r & -12.62 & 42.66 & 20.99 & -12.74 & -7.70 \\
\hline Q-12W-10_r & $19.73^{* *}$ & 20.92 & 6.14 & -12.89 & 12.54 \\
\hline Q-12L-10_r & 5.42 & 34.11 & 14.92 & -9.94 & -4.16 \\
\hline Q-12W-15_r & $24.10^{* *}$ & 19.98 & 5.77 & -13.43 & 12.24 \\
\hline Q-12L-15_r & 1.09 & 30.56 & 11.74 & -9.35 & -3.76 \\
\hline Q-12W-20_r & $16.15^{* *}$ & 19.50 & 5.92 & -13.04 & 11.60 \\
\hline Q-12L-20_r & -0.63 & 28.55 & 10.13 & -11.15 & -4.75 \\
\hline Q-4W-5_r & 33.75 & 27.53 & 8.56 & -12.34 & 13.59 \\
\hline Q-4L-5_r & -3.01 & 43.06 & 22.57 & -12.38 & 8.96 \\
\hline Q-4W-10_r & 27.00 & 23.12 & 7.47 & -12.01 & 14.04 \\
\hline Q-4L-10_r & 14.45 & 33.48 & 14.46 & -10.30 & 4.01 \\
\hline Q-4W-15_r & $28.99^{*}$ & 21.79 & 6.78 & -12.30 & 12.84 \\
\hline Q-4L-15_r & 9.39 & 30.00 & 11.78 & -8.47 & 5.16 \\
\hline Q-4W-20_r & $23.00^{*}$ & 20.97 & 6.50 & -11.90 & 12.01 \\
\hline Q-4L-20_r & 4.07 & 27.59 & 9.81 & -8.26 & 2.81 \\
\hline A-12W-5_r & $24.90^{* *}$ & 27.30 & 9.00 & -12.75 & 14.13 \\
\hline A-12L-5_r & -9.86 & 36.02 & 16.28 & -12.17 & -0.46 \\
\hline A-12W-10_r & 19.83 & 23.40 & 7.09 & -13.50 & 13.31 \\
\hline A-12L-10_r & 12.73 & 31.03 & 14.92 & -9.23 & 5.30 \\
\hline A-12W-15_r & 25.10 & 20.95 & 6.51 & -12.14 & 11.74 \\
\hline A-12L-15_r & 10.57 & 28.65 & 11.91 & -9.21 & 5.75 \\
\hline A-12W-20_r & 17.57 & 20.08 & 6.13 & -11.88 & 11.44 \\
\hline A-12L-20_r & 10.49 & 26.61 & 10.15 & -8.74 & 8.51 \\
\hline A-4W-5_r & 24.70 & 26.51 & 9.57 & -8.42 & 11.78 \\
\hline A-4L-5_r & 11.59 & 37.83 & 22.57 & -15.35 & 25.08 \\
\hline A-4W-10_r & 19.70 & 21.82 & 5.81 & -6.42 & 11.44 \\
\hline A-4L-10_r & 16.65 & 31.38 & 14.46 & -12.96 & 14.46 \\
\hline A-4W-15_r & 25.07 & 20.15 & 6.28 & -7.30 & 12.96 \\
\hline A-4L-15_r & 10.00 & 28.76 & 11.78 & -10.80 & 12.67 \\
\hline A-4W-20_r & 24.45 & 19.70 & 4.82 & -8.41 & 13.98 \\
\hline A-4L-20_r & 13.14 & 26.79 & 9.81 & -10.29 & 9.65 \\
\hline
\end{tabular}

Note. Portfolio refers to each of the portfolios generated based on the proposed methodology, named according to the nomenclature described in section 3. Median refers to the median of the portfolio's daily net return. Standard deviation refers to the standard deviation of the portfolio's daily net return. Maximum and Minimum refer to the maximum and minimum daily net returns presented by the portfolio over the period evaluated. Net profit refers to the return achieved by the portfolio over the period, discounted transaction costs. All data are presented in percentages. The Median, Standard deviation and Net profit are presented per annum to facilitate reader's interpretation. The one-tailed Mann-Whitney-Wilcoxon test was used to evaluate whether the medians of the winner portfolios were significantly higher than those of the loser portfolios. ${ }^{*}$ and ${ }^{* *}$ indicate statistically significance level of $10 \%$ and $5 \%$ respectively. None of the differences were significant at the level of $1 \%$. 
BBR

17

514

Table 2

Portfolios formed based on past alphas

\begin{tabular}{|c|c|c|c|c|c|}
\hline Portfolio & Median & Standard deviation & Maximum & Minimum & Net return \\
\hline Q-12W-5_ $\alpha$ & $27.29^{* *}$ & 25.82 & 8.08 & -13.78 & 21.05 \\
\hline Q-12L-5_ $\alpha$ & -3.53 & 40.76 & 18.85 & -12.40 & 2.12 \\
\hline Q-12W-10_ $\alpha$ & $18.80^{*}$ & 22.24 & 6.14 & -12.89 & 14.89 \\
\hline Q-12L-10_ $\alpha$ & 7.18 & 32.32 & 13.75 & -9.95 & -1.27 \\
\hline Q-12W-15_a & $20.96^{* *}$ & 21.21 & 6.15 & -12.52 & 14.78 \\
\hline Q-12L-15_ $\alpha$ & 4.55 & 29.36 & 11.74 & -10.42 & -5.33 \\
\hline Q-12W-20_ $\alpha$ & $16.94^{* *}$ & 20.86 & 6.03 & -12.35 & 15.20 \\
\hline Q-12L-20_ $\alpha$ & -2.75 & 27.54 & 9.98 & -11.58 & -6.89 \\
\hline Q-4W-5_ $\alpha$ & 27.13 & 28.29 & 9.94 & -12.34 & 18.32 \\
\hline Q-4L-5_ $\alpha$ & 8.70 & 42.18 & 22.57 & -12.38 & 15.10 \\
\hline Q-4W-10_ $\alpha$ & 24.35 & 23.63 & 7.04 & -12.01 & 15.64 \\
\hline Q-4L-10_ $\alpha$ & 7.37 & 32.20 & 13.95 & -9.74 & 5.45 \\
\hline Q-4W-15_ $\alpha$ & 28.32 & 22.07 & 6.50 & -13.14 & 15.83 \\
\hline Q-4L-15_ $\alpha$ & 9.32 & 28.78 & 11.73 & -9.82 & 5.14 \\
\hline Q-4W-20_ $\alpha$ & $17.60^{*}$ & 21.36 & 6.11 & -11.49 & 14.13 \\
\hline Q-4L-20_a & 7.72 & 26.91 & 9.50 & -8.38 & 3.31 \\
\hline A-12W-5_ $\alpha$ & 32.06 & 28.71 & 8.35 & -15.63 & 14.34 \\
\hline A-12L-5_ $\alpha$ & 10.37 & 36.34 & 18.85 & -12.40 & 5.16 \\
\hline A-12W-10_ $\alpha$ & 18.88 & 23.63 & 6.24 & -12.34 & 14.24 \\
\hline A-12L-10_ $\alpha$ & 15.47 & 29.78 & 13.75 & -9.95 & 7.18 \\
\hline A-12W-15_ $\alpha$ & 19.01 & 22.11 & 6.55 & -11.62 & 13.06 \\
\hline A-12L-15_ $\alpha$ & 12.76 & 27.78 & 11.74 & -8.88 & 5.44 \\
\hline 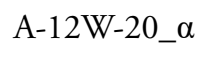 & 17.25 & 21.45 & 5.81 & -11.23 & 11.78 \\
\hline A-12L-20_a & 9.80 & 25.61 & 9.98 & -8.37 & 5.75 \\
\hline 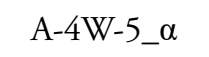 & 11.93 & 28.34 & 9.94 & -8.67 & 8.15 \\
\hline A-4L-5_ $\alpha$ & 10.44 & 37.69 & 22.57 & -15.35 & 18.75 \\
\hline A-4W-10_ $\alpha$ & 22.43 & 23.35 & 6.13 & -6.44 & 10.15 \\
\hline A-4L-10_ $\alpha$ & 16.02 & 30.18 & 13.95 & -12.96 & 12.75 \\
\hline A-4W-15_a & 24.84 & 21.49 & 5.39 & -7.69 & 13.92 \\
\hline A-4L-15_ $\alpha$ & 15.60 & 27.75 & 11.73 & -11.15 & 11.50 \\
\hline A-4W-20_ $\alpha$ & 20.37 & 20.63 & 5.27 & -9.03 & 14.16 \\
\hline A-4L-20_ $\alpha$ & 15.41 & 26.33 & 9.50 & -10.17 & 7.86 \\
\hline
\end{tabular}

Note. Portfolio refers to each of the portfolios generated based on the proposed methodology, named according to the nomenclature described in section 3. Median refers to the median of the portfolio's daily net return. Standard deviation refers to the standard deviation of the portfolio's daily net return. Maximum and Minimum refer to the maximum and minimum daily net returns presented by the portfolio over the period evaluated. Net profit refers to the return achieved by the portfolio over the period, discounted transaction costs. All data are presented in percentages. The Median, Standard deviation, and Net profit are presented per annum to facilitate reader's interpretation. The one-tailed Mann-Whitney-Wilcoxon test was used to evaluate whether the medians of the winner portfolios were significantly higher than those of the loser portfolios. ${ }^{*}$ and ${ }^{* *}$ indicate statistically significance level of $10 \%$ and $5 \%$ respectively. None of the differences were significant at the level of $1 \%$. 
For illustrative matters, Figures 1 to 3 present how the wealth of investors who had chosen to follow each of the three strategies that significantly outperformed the ETF would develop over the time.

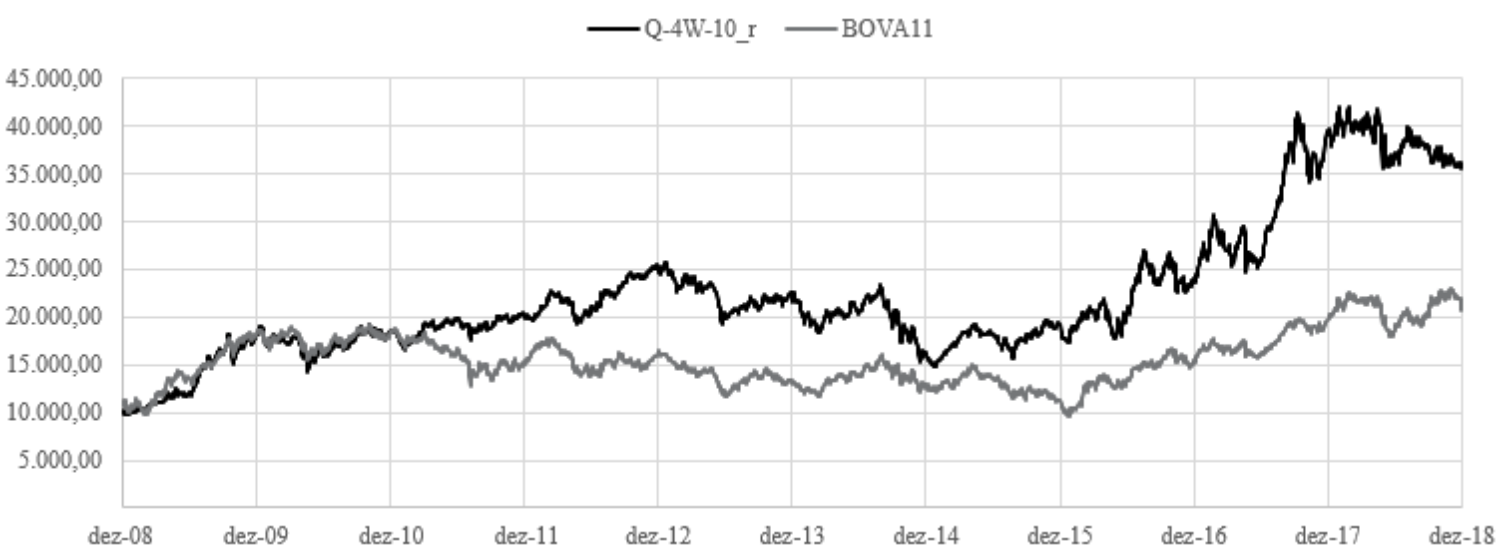

Figure 1. Wealth development: Q-4W-10_r vs. BOVA11

Source: Simulation made by authors.
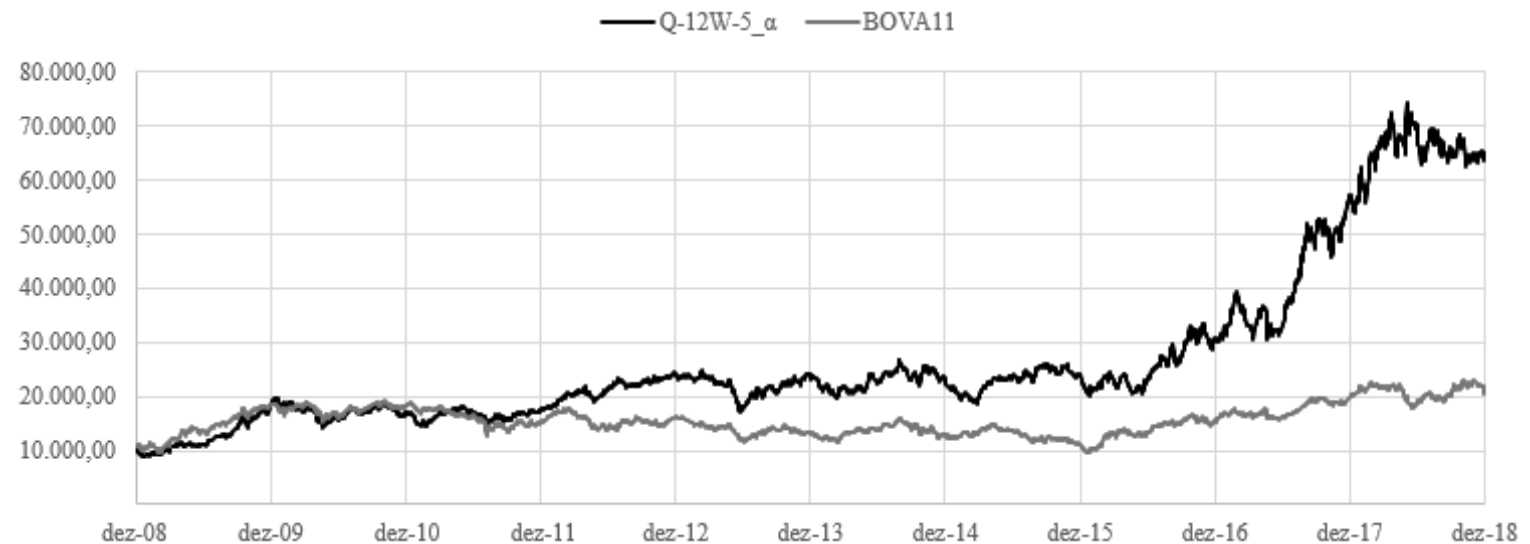

Figure 2. Wealth development: Q-12W-5_ $\alpha$ vs. BOVA11.

Source: Simulation made by authors.

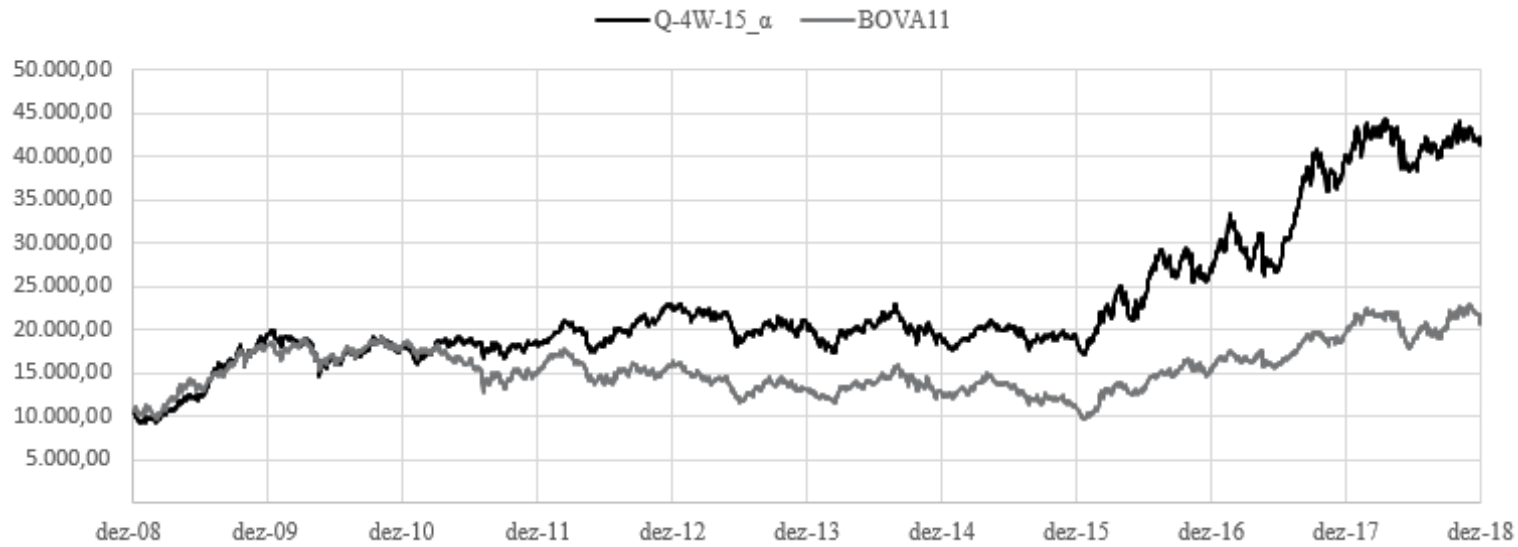

Figure 3. Wealth development: Q-4W-15_a vs. BOVA11.

Source: Simulation made by authors. 
BBR

17

516

Table 3

Portfolios composed of winner assets vs. Ibovespa Exchange Traded Fund

\begin{tabular}{|c|c|c|c|c|c|c|}
\hline Portfolio & Median & $\begin{array}{l}\text { Standard } \\
\text { deviation }\end{array}$ & Net profit & Sharpe ratio & Alpha & Beta \\
\hline Q-12W-5_r & 15.52 & 24.56 & 13.47 & 0.2408 & 5.74 & 0.5680 \\
\hline Q-12W-10_r & 19.73 & 20.92 & 12.54 & 0.2036 & 4.00 & 0.5869 \\
\hline Q-12W-15_r & 24.10 & 19.98 & 12.24 & 0.1902 & 3.51 & 0.6068 \\
\hline Q-12W-20_r & 16.15 & 19.50 & 11.60 & 0.1606 & 2.81 & 0.6183 \\
\hline Q-4W-5_r & 33.75 & 27.53 & 13.59 & 0.2466 & 6.59 & 0.6989 \\
\hline Q-4W-10_r & $27.00^{*}$ & 23.12 & 14.04 & 0.2623 & 5.85 & 0.6615 \\
\hline Q-4W-15_r & 28.99 & 21.79 & 12.84 & 0.2162 & 4.41 & 0.6759 \\
\hline Q-4W-20_r & 23.00 & 20.97 & 12.01 & 0.1813 & 3.47 & 0.6822 \\
\hline A-12W-5_r & 24.90 & 27.30 & 14.13 & 0.2638 & 7.07 & 0.6403 \\
\hline A-12W-10_r & 19.83 & 23.40 & 13.31 & 0.2348 & 5.24 & 0.6596 \\
\hline A-12W-15_r & 25.10 & 20.95 & 11.74 & 0.1694 & 3.24 & 0.6214 \\
\hline A-12W-20_r & 17.57 & 20.08 & 11.44 & 0.1549 & 2.79 & 0.6183 \\
\hline A-4W-5_r & 24.70 & 26.51 & 11.78 & 0.1847 & 4.63 & 0.6454 \\
\hline A-4W-10_r & 19.70 & 21.82 & 11.44 & 0.1588 & 3.16 & 0.6080 \\
\hline A-4W-15_r & 25.07 & 20.15 & 12.96 & 0.2217 & 4.20 & 0.6159 \\
\hline A-4W-20_r & 24.45 & 19.70 & 13.98 & 0.2682 & 5.03 & 0.6434 \\
\hline Q-12W-5_ $\alpha$ & $27.29^{*}$ & 25.82 & 21.05 & 0.4918 & $13.11^{*}$ & 0.6495 \\
\hline Q-12W-10_ $\alpha$ & 18.80 & 22.24 & 14.89 & 0.2973 & 6.42 & 0.6670 \\
\hline Q-12W-15_a & 20.96 & 21.21 & 14.78 & 0.2968 & 6.08 & 0.6817 \\
\hline Q-12W-20_ $\alpha$ & 16.94 & 20.86 & 15.20 & 0.3157 & 6.38 & 0.6927 \\
\hline Q-4W-5_a & 27.13 & 28.29 & 18.32 & 0.3915 & 11.21 & 0.7665 \\
\hline Q-4W-10_ $\alpha$ & 24.35 & 23.63 & 15.64 & 0.3208 & 7.42 & 0.7315 \\
\hline Q-4W-15_ $\alpha$ & $28.32^{*}$ & 22.07 & 15.83 & 0.3349 & 7.22 & 0.7156 \\
\hline Q-4W-20_ $\alpha$ & 17.60 & 21.36 & 14.13 & 0.2696 & 5.49 & 0.7236 \\
\hline A-12W-5_ $\alpha$ & 32.06 & 28.71 & 14.34 & 0.2714 & 7.62 & 0.7695 \\
\hline A-12W-10_ $\alpha$ & 18.88 & 23.63 & 14.24 & 0.2693 & 6.14 & 0.7005 \\
\hline A-12W-15_a & 19.01 & 22.11 & 13.06 & 0.2250 & 4.67 & 0.7064 \\
\hline A-12W-20_ $\alpha$ & 17.25 & 21.45 & 11.78 & 0.1721 & 3.34 & 0.7086 \\
\hline A-4W-5_ $\alpha$ & 11.93 & 28.34 & 8.15 & 0.0737 & 1.65 & 0.7756 \\
\hline A-4W-10_ $\alpha$ & 22.43 & 23.35 & 10.15 & 0.1131 & 2.26 & 0.7096 \\
\hline A-4W-15_ $\alpha$ & 24.84 & 21.49 & 13.92 & 0.2604 & 5.33 & 0.6985 \\
\hline A-4W-20_ $\alpha$ & 20.37 & 20.63 & 14.16 & 0.2728 & 5.36 & 0.6964 \\
\hline BOVA11 & 8.29 & 24.34 & 10.24 & 0.0237 & 0.00 & 1.0000 \\
\hline
\end{tabular}

Note. All data are expressed in percentage, except the Sharpe ratio and Beta. All parameters except Beta are presented in annual terms to facilitate reader's interpretation. The median of each portfolio was analyzed aiming to identify whether they significantly outperformed the median of the BOVA11 ETF, by applying the one-tailed Mann-Whitney-Wilcoxon test. It was also evaluated whether the alphas of the portfolios were significantly positive, applying the Student's t-test. ${ }^{*}$ and ${ }^{* *}$ indicate statistically significance level of $10 \%$ and $5 \%$ respectively. None of the differences were significant at the level of $1 \%$. 
Under this risk-return perspective, the proposed portfolios largely dominated the ETF. In the least-favorable scenario, the portfolio's Sharpe ratio was two times higher than the BOVA11's, whereas, in the best case, the portfolio's SR was twenty times higher than the ETF's. It is noteworthy that none of the values were negative, which eliminated the need to adjust the Sharpe ratio to remove an eventual bias, as proposed by Israelsen (2005).

Aligned with this analysis, the evaluation, though the Capital Asset Pricing Model (CAPM), also indicates a large advantage in favor of the proposed portfolios. All of them shown Beta below 1 , suggesting a lower systemic risk when compared to the market. Therefore, due to the aforementioned return superiority, the 32 winner portfolios generated alphas in the period. The only point of attention is the fact that only one of the values was significantly different from zero which inspires a little caution when interpreting the data.

\subsection{The INFLUENCE OF TRANSACTION COSTS}

Complementing the previous analysis, an additional test regarding the impact of transaction costs on the investor's final net profit was conducted. The main purpose of this test was to understand whether higher brokerage fees would reduce the final net profit to the point of jeopardizing the feasibility of the proposed model.

For this study, three possible brokerage fee rates were considered: BRL 0.00, BRL 5.00 (base case) and BRL 15.00. These amounts are in line with the conditions practiced by the main brokers in the country. Table 4 shows the final wealth achieved by each winner portfolio at the end of the period (December 2018), in each of the previously described scenarios.

As expected, transaction costs most significantly affect portfolios that are frequently reviewed and those with higher number of stocks. The variation in the final value achieved by the passive management portfolio (BOVA11) is practically null, as the strategy did not contemplate intermediate investments - nor withdrawals - over the period.

In the scenario where brokerage fees were more aggressive (BRL 15.00), 11 portfolios failed to achieve cumulative return higher than the benchmark after ten years. Of the ones reviewed every four months, half lose competitiveness, as do about half of the ones composed of a high number of stocks (15 or 20). Presumably, these same portfolios benefited the most from the scenario of zero brokerage fees; in the best cases, the increase in final wealth reached about $40 \%$.

Deepening the analysis, in Table 5, the descriptive statistics of the winner portfolios are once again gathered, although, now considering the best-case scenario in terms of transaction costs (null brokerage fees).

Under such scenario, not only is the disparity between the performances of the proposed portfolios and the index fund increases, but also the statistical significance of the results is greatly improved, ratifying the importance of keeping transaction costs as low as possible. 
BBR

17

518

Table 4

Impact of transaction costs on the net profit of the winner portfolios

\begin{tabular}{|c|c|c|c|c|c|}
\hline \multirow{2}{*}{ Portfolio } & \multicolumn{2}{|c|}{ BRL 0.00} & \multirow{2}{*}{$\begin{array}{c}\text { BRL } 5.00 \\
\text { Final wealth }\end{array}$} & \multicolumn{2}{|c|}{ BRL 15.00} \\
\hline & Final wealth & Variation & & Final wealth & Variation \\
\hline Q-12W-5_r & $36,802.21$ & 6.62 & $34,517.17$ & $29,029.91$ & -15.90 \\
\hline Q-12W-10_r & $37,334.51$ & 17.28 & $31,834.67$ & $20,142.17$ & -36.73 \\
\hline Q-12W-15_r & $38,117.81$ & 22.96 & $31,001.22$ & $13,028.62$ & -57.97 \\
\hline Q-12W-20_r & $40,803.94$ & 39.22 & $29,309.78$ & $1,474.37$ & -94.97 \\
\hline Q-4W-5_r & $36,730.74$ & 5.35 & $34,865.69$ & $28,909.92$ & -17.08 \\
\hline Q-4W-10_r & $40,291.34$ & 11.21 & $36,230.01$ & $26,803.15$ & -26.02 \\
\hline Q-4W-15_r & $40,283.62$ & 23.33 & $32,662.44$ & $18,779.30$ & -42.50 \\
\hline Q-4W-20_r & $40,775.06$ & 34.12 & $30,402.00$ & $8,210.33$ & -72.99 \\
\hline A-12W-5_r & $38,010.97$ & 4.06 & $36,528.41$ & $33,563.30$ & -8.12 \\
\hline A-12W-10_r & $36,798.09$ & 8.11 & $34,036.41$ & $28,513.06$ & -16.23 \\
\hline A-12W-15_r & $33,311.30$ & 12.26 & $29,673.84$ & $22,398.94$ & -24.52 \\
\hline A-12W-20_r & $33,437.16$ & 15.60 & $28,924.18$ & $19,898.22$ & -31.21 \\
\hline A-4W-5_r & $31,407.25$ & 5.48 & $29,776.51$ & $26,515.03$ & -10.95 \\
\hline A-4W-10_r & $31,525.10$ & 9.04 & $28,911.65$ & $23,657.88$ & -18.17 \\
\hline A-4W-15_r & $36,707.83$ & 11.22 & $33,004.13$ & $26,483.22$ & -19.76 \\
\hline A-4W-20_r & $41,377.99$ & 14.73 & $36,065.90$ & $26,667.21$ & -26.06 \\
\hline Q-12W-5_ $\alpha$ & $69,850.11$ & 7.38 & $65,052.01$ & $55,446.47$ & -14.77 \\
\hline Q-12W-10_ $\alpha$ & $45,090.73$ & 15.67 & $38,982.44$ & $25,739.85$ & -33.97 \\
\hline Q-12W-15_a & $47,295.14$ & 22.44 & $38,627.93$ & $18,544.83$ & -51.99 \\
\hline Q-12W-20_a & $54,741.73$ & 36.77 & $40,024.90$ & $11,778.14$ & -70.57 \\
\hline Q-4W-5_a & $55,852.18$ & 7.37 & $52,019.17$ & $45,262.73$ & -12.99 \\
\hline Q-4W-10_ $\alpha$ & $46,779.97$ & 12.57 & $41,557.57$ & $29,560.58$ & -28.87 \\
\hline Q-4W-15_ $\alpha$ & $50,900.48$ & 20.56 & $42,219.31$ & $24,152.46$ & -42.79 \\
\hline Q-4W-20_ $\alpha$ & $49,380.64$ & 35.14 & $36,540.21$ & $12,427.85$ & -65.99 \\
\hline A-12W-5_ $\alpha$ & $39,201.99$ & 5.38 & $37,202.14$ & $33,202.44$ & -10.75 \\
\hline A-12W-10_ $\alpha$ & $39,887.67$ & 8.16 & $36,878.39$ & $30,859.84$ & -16.32 \\
\hline A-12W-15_a & $37,369.75$ & 12.21 & $33,304.81$ & $25,174.92$ & -24.41 \\
\hline A-12W-20_ $\alpha$ & $34,610.32$ & 16.19 & $29,787.06$ & $20,140.53$ & -32.38 \\
\hline A-4W-5_ $\alpha$ & $22,798.46$ & 5.82 & $21,545.25$ & $19,038.81$ & -11.63 \\
\hline A-4W-10_ $\alpha$ & $28,182.79$ & 9.27 & $25,791.50$ & $20,979.53$ & -18.66 \\
\hline A-4W-15_ $\alpha$ & $40,027.76$ & 11.56 & $35,878.67$ & $29,286.81$ & -18.37 \\
\hline A-4W-20_ $\alpha$ & $41,963.91$ & 14.57 & $36,628.09$ & $27,309.38$ & -25.44 \\
\hline BOVA11 & $20,599.70$ & 0.05 & $20,590.05$ & $20,570.76$ & -0.09 \\
\hline
\end{tabular}

Note. Final wealth refers to the portfolio's net value at the end of the period (in BRL), considering the brokerage fee shown in the respective column. Variation is the percentage increase or decrease in the portfolio's final wealth as a result of the change in the brokerage fee, that is, compared with the same portfolio's final wealth, but in the base case (BRL 5.00). 
Table 5

Winner portfolios' performances considering null brokerage fees

\begin{tabular}{|c|c|c|c|c|c|c|}
\hline Portfolio & Median & Standard deviation & Net profit & Sharpe ratio & Alpha & Beta \\
\hline Q-12W-5_r & 17.15 & 24.58 & 14.22 & 0.2674 & 6.44 & 0.5695 \\
\hline Q-12W-10_r & 21.07 & 20.90 & 14.39 & 0.2815 & 5.69 & 0.5896 \\
\hline Q-12W-15_r & 26.64 & 19.93 & 14.63 & 0.2959 & 5.70 & 0.6097 \\
\hline Q-12W-20_r & 18.79 & 19.38 & 15.43 & 0.3346 & 6.31 & 0.6225 \\
\hline Q-4W-5_r & $34.59^{*}$ & 27.54 & 14.19 & 0.2659 & 7.16 & 0.6995 \\
\hline Q-4W-10_r & $28.11^{*}$ & 23.14 & 15.28 & 0.3092 & 7.00 & 0.6632 \\
\hline Q-4W-15_r & $29.97^{*}$ & 21.76 & 15.28 & 0.3145 & 6.66 & 0.6786 \\
\hline Q-4W-20_r & $23.52^{*}$ & 20.93 & 15.42 & 0.3243 & 6.60 & 0.6866 \\
\hline A-12W-5_r & 25.42 & 27.29 & 14.59 & 0.2787 & 7.50 & 0.6405 \\
\hline A-12W-10_r & 20.33 & 23.37 & 14.22 & 0.2688 & 6.07 & 0.6600 \\
\hline A-12W-15_r & 25.94 & 20.89 & 13.06 & 0.2258 & 4.45 & 0.6221 \\
\hline A-12W-20_r & 18.35 & 19.99 & 13.11 & 0.2287 & 4.30 & 0.6192 \\
\hline A-4W-5_r & 24.70 & 26.49 & 12.39 & 0.2052 & 5.19 & 0.6452 \\
\hline A-4W-10_r & 19.79 & 21.77 & 12.43 & 0.1992 & 4.06 & 0.6082 \\
\hline A-4W-15_r & 25.64 & 20.08 & 14.19 & 0.2758 & 5.31 & 0.6166 \\
\hline A-4W-20_r & 24.89 & 19.60 & 15.59 & 0.3401 & $6.49^{*}$ & 0.6444 \\
\hline Q-12W-5_ $\alpha$ & $27.93^{*}$ & 25.82 & 21.93 & 0.5200 & $13.93^{* *}$ & 0.6505 \\
\hline Q-12W-10_ $\alpha$ & 19.42 & 22.24 & 16.61 & 0.3641 & 8.01 & 0.6702 \\
\hline Q-12W-15_ $\alpha$ & 22.24 & 21.19 & 17.18 & 0.3944 & $8.28^{*}$ & 0.6845 \\
\hline Q-12W-20_ $\alpha$ & $19.59^{*}$ & 20.75 & 18.94 & 0.4702 & $9.80^{* *}$ & 0.6964 \\
\hline Q-4W-5_ $\alpha$ & 26.22 & 28.29 & 19.18 & 0.4172 & $12.02^{*}$ & 0.7674 \\
\hline Q-4W-10_ $\alpha$ & 24.82 & 23.66 & 17.05 & 0.3718 & $8.73^{*}$ & 0.7336 \\
\hline Q-4W-15_ $\alpha$ & $28.44^{*}$ & 22.05 & 18.06 & 0.4215 & $9.28^{* *}$ & 0.7182 \\
\hline Q-4W-20_ $\alpha$ & $19.42^{*}$ & 21.29 & 17.70 & 0.4141 & $8.75^{* *}$ & 0.7274 \\
\hline A-12W-5_ $\alpha$ & 32.21 & 28.70 & 14.96 & 0.2900 & 8.19 & 0.7695 \\
\hline A-12W-10_ $\alpha$ & 19.46 & 23.60 & 15.16 & 0.3033 & 6.98 & 0.7009 \\
\hline A-12W-15_ $\alpha$ & 19.60 & 22.05 & 14.40 & 0.2783 & 5.89 & 0.7070 \\
\hline A-12W-20_ $\alpha$ & 18.07 & 21.36 & 13.50 & 0.2436 & 4.91 & 0.7093 \\
\hline A-4W-5_ $\alpha$ & 11.93 & 28.30 & 8.77 & 0.0938 & 2.23 & 0.7753 \\
\hline A-4W-10_ $\alpha$ & 22.43 & 23.30 & 11.15 & 0.1517 & 3.17 & 0.7096 \\
\hline A-4W-15_a & 25.59 & 21.42 & 15.20 & 0.3127 & 6.49 & 0.6991 \\
\hline A-4W-20_a & 20.69 & 20.54 & 15.76 & 0.3407 & $6.81^{*}$ & 0.6974 \\
\hline BOVA11 & 8.29 & 24.34 & 10.24 & 0.0239 & 0.00 & 1.0000 \\
\hline
\end{tabular}

Note. All data are expressed in percentage, except the Sharpe ratio and Beta. All parameters except Beta are presented in annual terms to facilitate reader's interpretation. The median of each portfolio was analyzed aiming to identify whether they significantly outperformed the median of the BOVA11 ETF, by applying the one-tailed Mann-Whitney-Wilcoxon test. It was also evaluated whether the alphas of the portfolios were significantly positive, applying the Student's t-test. ${ }^{*}$ and ${ }^{* *}$ indicate statistically significance level of $10 \%$ and $5 \%$ respectively. None of the differences were significant at the level of $1 \%$. 


\section{CONCLUSION}

This study analyzed the persistence in returns in the Brazilian stock market through strategies structured around the so called "momentum effect", with special focus on the unsophisticated investor. This research brought new evidence that points to the existence of a "momentum effect" in the Brazilian stock market. It is noteworthy that all portfolios composed of winner stocks showed higher median returns than those composed of loser assets (all other variables constant), regardless of the selection criteria (past returns or alphas). Moreover, the evaluation of the performance of equally weighted portfolios formed according to past alphas in the Brazilian market can be considered by itself a relevant contribution of the work.

It is important to mention that, in the base brokerage fee case, the statistical significance of such superiority was concentrated in a specific portfolio profile (the ones reviewed every four months and formed by the assets that had shown higher returns on the past year). Therefore, the interpretation of the performance achieved by others must be carried out with caution.

In regards to the unsophisticated investor, the main result presented was that all winner portfolios outperformed not only their respective losers but also one of the most representative passive management strategies available in the market (the ETF BOVA11, which seeks to replicate the leading Brazilian stock market index, Ibovespa), even when considering all transaction costs. The median net returns of all winner portfolios were higher than the benchmark, having most of them also shown lower volatility. For sophisticated investors, a long-short strategy with winner and loser portfolios seems very appealing.

However, a point of attention must be brought to the discussion. Even though all winner portfolios presented median returns higher than the BOVA11 index fund, the differences were only significant at a $10 \%$ level in 03 of the 32 cases. This evidence combined with the fact that the methodology was applied over a single period of time gives no guarantee that the disparity observed will be repeated in the future. To mitigate this doubt, a suggestion for future works is the replication of such rationale in other periods of time, aiming to generate more data that support the competitiveness of the strategies proposed by this article.

Still focusing on the unsophisticated investor, the results of the additional tests must be emphasized. This data shows that it is of paramount importance for such investor to be aware of transaction costs, as well as to employ efforts to reduce them as much as possible. Aggressive brokerage fees tend to destroy the investor's wealth in the long-term, especially in the case of portfolios frequently reviewed and/or composed by a high number of assets. Therefore, considering such results and the recent reduction in brokerage fees in Brazil, another suggestion for future works is to review the competitiveness of active management strategies that have been rendered unfeasible by (higher) transaction costs in the past.

In conclusion, there are representative evidences of "momentum effect" in the Brazilian stock market, which may be translated into efficient investment opportunities. Equally weighted portfolios with winner stocks are easy-to-implement and manageable alternatives even for unsophisticated and/or small investors: These strategies are also shown to be highly competitive under the risk and return perspective, provided that transaction costs remain under control. 


\section{REFERENCES}

Battaglia, T. K., Leal, R. P. C. (2017). Equally Weighted Portfolios of Randomly Selected Stocks and the Individual Investor. Latin American Business Review, 18(1), 69-90.

Benartzi, S., Thaler R. H. (2001). Naive Diversification Strategies in Defined Contribution Saving Plans. American Economic Review, 91(1), 79-98.

Brito, N. R. O. (1989). O efeito da diversificação de risco no mercado acionário brasileiro. In N. R. O. Brito (Org.), Gestão de investimentos (pp. 81-104). São Paulo: Atlas.

Carneiro, A., Leal, R. P. C. (2017). Naive portfolios, Brazilian stock funds, and individual investors. Academia Revista Latinoamericana de Administración, 30(3), 383-401.

DeMiguel, V., Garlappi, L., Uppal, R. (2009). Optimal Versus Naive Diversification: How Inefficient is the 1-N Portfolio Strategy? Review of Financial Studies, 22(5), 1915-1953.

Duchin, R., Levy, H. (2009). Markowitz Versus the Talmudic Portfolio Diversification Strategies. The Journal of Portfolio Management, 35(2), 71-74.

Ecossistema do Investidor Brasileiro. (2019). Retrieved from http://www.b3.com.br/

Fama, E. F. (1970). Efficient Capital Markets: A Review of Theory and Empirical Work. The Journal of Finance, 25(2), 383-417.

Israelsen, C. (2005). A refinement to the Sharpe ratio and information ratio. Journal of Asset Management, 5(6), 423-427.

Jegadeesh, N., Titman, S. (1993). Returns to Buying Winners and Selling Losers: Implications for Stock Market Efficiency. The Journal of Finance, 48(1), 65-91.

Jegadeesh, N., Titman, S. (2001). Profitability of Momentum Strategies: An Evaluation of Alternative Explanations. The Journal of Finance, 56(2), 699-720.

Jensen, M. C. (1968). The Performance of Mutual Funds in the Period 1945-1964. Journal of Finance, 23(2), 389-416.

Kritzman, M., Page, S., Turkington, D. (2010). In Defense of Optimization: The Fallacy of 1/ N. Financial Analysts Journal, 66(2), 31-39.

Leal, R. P. C., Campani, C. H. (2016). Índices Valor-Coppead, Carteiras de Ponderação Igualitária e de Mínima Variância. Revista Brasileira de Finanças, 14(1), 45-64.

Leoni, J. E. M. (2015). Análise dos efeitos momento e contrário no mercado acionário brasileiro. (Dissertação de Mestre). Universidade de Sáo Paulo, SP, Brasil.

Markowitz, H. (1952). Portfolio Selection. The Journal of Finance, 7(1), 77-91.

Mendonça Júnior, J. A., Campani, C. H., Leal, R. P. C. (2017). A Escolha de Fundos de Açóes e o Investidor Individual. Revista de Administração Contemporânea, 21(3), 41-62.

Mengoli, S. (2004). On the Source of Contrarian and Momentum Strategies in the Italian Equity Market. International Review of Financial Analysis, 13(3), 301-331.

Mussa, A., Trovão, R., Santos, J. O. dos, Famá, R. (2007). A estratégia de momento de Jegadeesh e Titman e suas implicaçóes para a hipótese de eficiência do mercado acionário brasileiro. Anais do SemeAd, São Paulo, SP, Brasil, 10.

Oliveira, F. N., de Paula, E. L. (2008). Determinando o Grau Ótimo de Diversificação para Investidores Usuários de Home Brokers. Revista Brasileira de Finanças, 6(3), 437-461. 
BBR

17

522

Pires, M. R. (2013). Os efeitos disponibilidade e momento no mercado acionário brasileiro - Um estudo empírico. (Dissertação de Mestre). Fundação Getúlio Vargas, SP, Brasil.

Rouwenhorst, K. G. (1998). International Momentum Strategies. The Journal of Finance, 53(1), 267-284.

Santiago, D. C., Leal, R. P. C. (2015). Carteiras Igualmente Ponderadas com Poucas Açóes e o Pequeno Investidor. Revista de Administração Contemporânea, 19(5), 544-564.

Schiereck, D., De Bondt, W., Weber, M. (1999). Contrarian and Momentum Strategies in Germany. Financial Analysts Journal, 55(6), 104-116.

Sharpe, W. F. (1966). Mutual fund performance. The Journal of Business, 39(1), 119-138.

Silva Neto, O. S., Silva, V. L. A. M. S., Raboni, P. L., Oliveira, M. R. G. (2014). Efeito momentum no curto prazo: vale a pena comprar açóes vencedoras no Brasil? RAM, Revista de Administração Mackenzie, 15(4), 193-228.

Swensen, D. (2009). Pioneering Portfolio Management: An Unconventional Approach to Institutional Investment (Revised, Updated ed.). Free Press.

Thomé Neto, C., Leal, R. P. C., Almeida, V. (2011). Um índice de mínima variância de ações Brasileiras. Economia Aplicada, 15(4), 535-557.

\section{ACKNOWLEDGMENTS}

Carlos Heitor Campani thanks you for supporting research from the following institutions: Brasilprev, Faperj e CNPq.

\section{CONFLICTS OF INTEREST}

The authors declare that there is no conflict of interest. Author Contributions: Author CHC, Formal analysis (Lead), Investigation (Lead) and Methodology (Lead); Author FC, Research Idea, Formal analysis (Supporting), Investigation (Supporting) and Methodology (Supporting); Author RR, Formal analysis (Supporting). 